\title{
Enhancing quality for clients: The balanced counseling strategy
}

Federico R. Leon

Alex Rios

Adriana Zumaran

Marisela de la Cruz

Carlos Brambila

See next page for additional authors

Follow this and additional works at: https://knowledgecommons.popcouncil.org/departments_sbsr-rh How does access to this work benefit you? Let us know!

\section{Recommended Citation}

Leon, Federico R., Alex Rios, Adriana Zumaran, Marisela de la Cruz, Carlos Brambila, and John H. Bratt. 2003. "Enhancing quality for clients: The balanced counseling strategy," FRONTIERS Program Brief. Washington, DC: Population Council. 


\section{Authors}

Federico R. Leon, Alex Rios, Adriana Zumaran, Marisela de la Cruz, Carlos Brambila, and John H. Bratt 


\section{Enhancing Quality for Clients: The Balanced Counseling Strategy}

central focus of high-
quality care is the inter-
action between clients and the providers who serve them. In the ideal clientprovider interaction, the provider treats all clients respectfully, responds to their reproductive needs and intentions, helps in the selection of the most appropriate family planning method, and offers sufficient information to use the method safely and effectively (Bruce 1990).

To improve the quality of the client-provider interaction, Population Council staff developed a "bal anced counseling strategy," a type of algorithm or decision tree, to be used in combination with several job aids, or visual memory aids. The balanced counsel ing strategy structures the clientprovider interaction to focus on the client's needs, support the client's choice of an appropriate method, and improve the information provided on the method. Studies in several sites have documented significant improvements in the client-provider interaction when providers use the balanced counseling strategy along with the job aids.

The balanced counseling strategy combines an algorithm for family planning counseling with a set of job aidscards and pamphlets on available methods. When providers use both the algorithm and job aids, the quality of counseling improves.

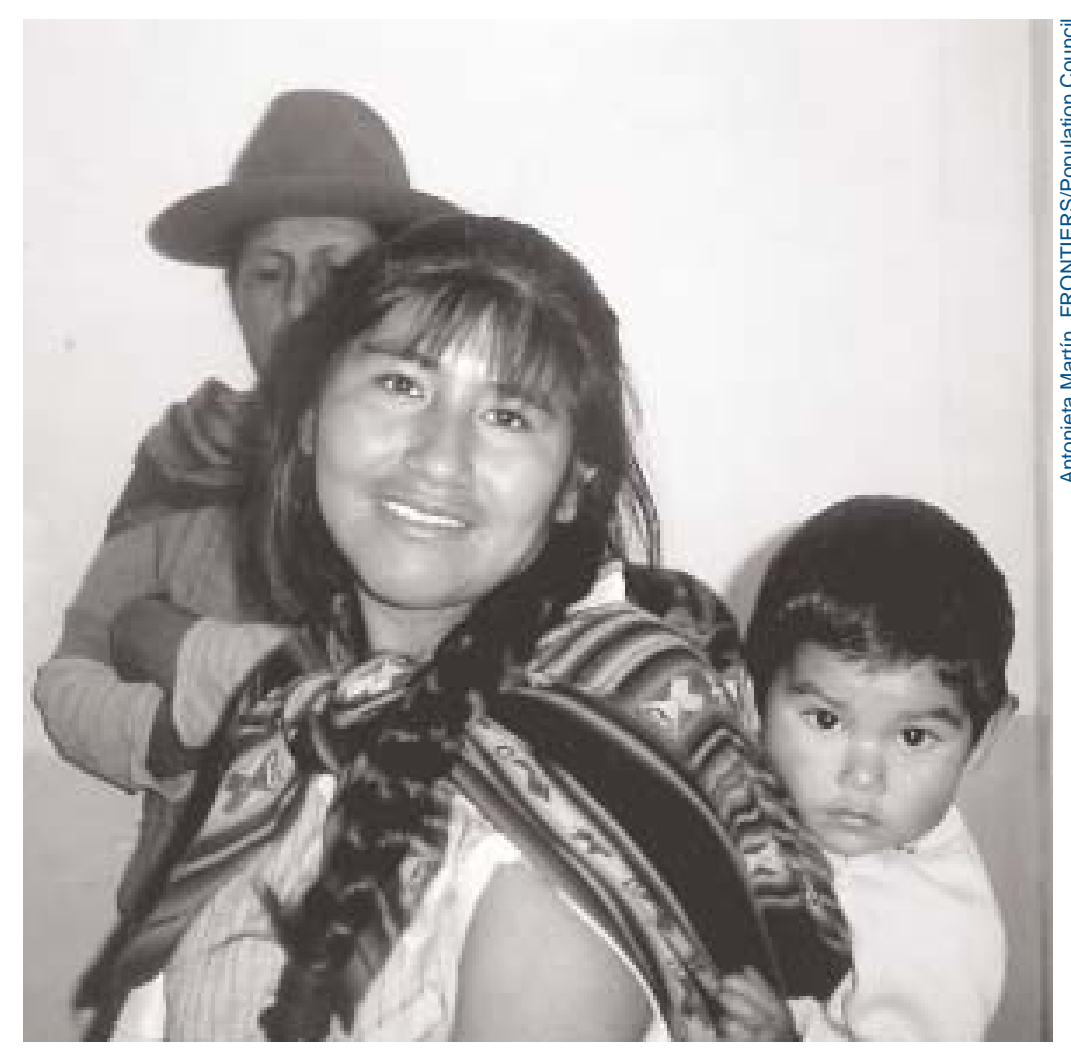

The balanced counseling strategy can enhance family planning counseling and increase informed choice for clients.
This Program Brief describes the balanced counseling strategy as an ongoing approach to improving quality of care. It outlines the origin and rationale for developing the strategy, and details its subsequent adaptation for use in other contexts.

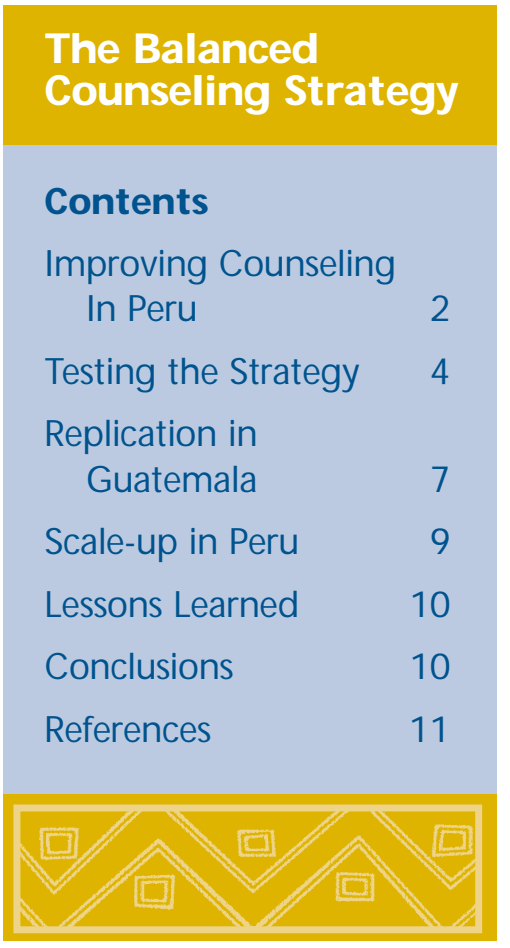



Frontiers in Reproductive Health
Program Brief No. 3

Authors: Federico R. León, Alex Ríos,
Adriana Zumarán, Marisela
de la Cruz, Carlos Brambila,
and John H. Bratt

Editors: Stephanie Joyce, Laura Raney, and Jim Foreit

Design: Vincent Hughes Visualization

The assistance of the following reviewers is appreciated: Susan Adamchak, Lauren Bocanegra, Sarah Harbison, Shawn Malarcher, John Townsend, and Ricardo Vemon.

Photos courtesy of Susan Adamchak, FRONTIERS/FHI and Antonieta Martín, FRONTIERS/Population Council.

Suggested citation: León et al. 2003. "Enhancing Quality for Clients: The Balanced Counseling Strategy," FRONTIERS Program Brief. No. 3. Washington, D.C.: Population Council.

The Frontiers in Reproductive Health Program (FRONTIERS) applies systematic research techniques to improve delivery of family planning and reproductive health services and influence related policies. FRONTIERS is funded by the U.S. Agency for International Development (USAID) and led by the Population Council in collaboration with Family Health International and Tulane University.

This publication was made possible through support provided by USAID under the terms of Cooperative Agreement No. HRN-A-00-98-00012. The opinions expressed herein do not necessarily reflect the views of USAID.

\section{(P) Population Council}

\section{fhi $\rightarrow$}

Tulane University

\section{Improving Counseling in Peru}

The balanced counseling strategy originated in research conducted in Peru to assess providers' compliance with national norms for family planning care. Peru has promoted family planning for decades through its National Family Planning Program, a division of the Peruvian Ministry of Health $(\mathrm{MOH})$.

In the late 1990s the Ministry modified its policies to enhance the quality of family planning services. A major rationale for this policy shift was an increased emphasis on informed choice for each client. New guidelines, issued in 1999, reflected the reforms and outlined a specific counseling process. The $\mathrm{MOH}$ directed providers to follow a five-step strategy consisting of: (1) a warm welcome; (2) diagnosis of the client's needs; (3) assis-

\section{Figure 1. Five-Step Counseling Process Outlined in the 1999 MOH Guidelines}

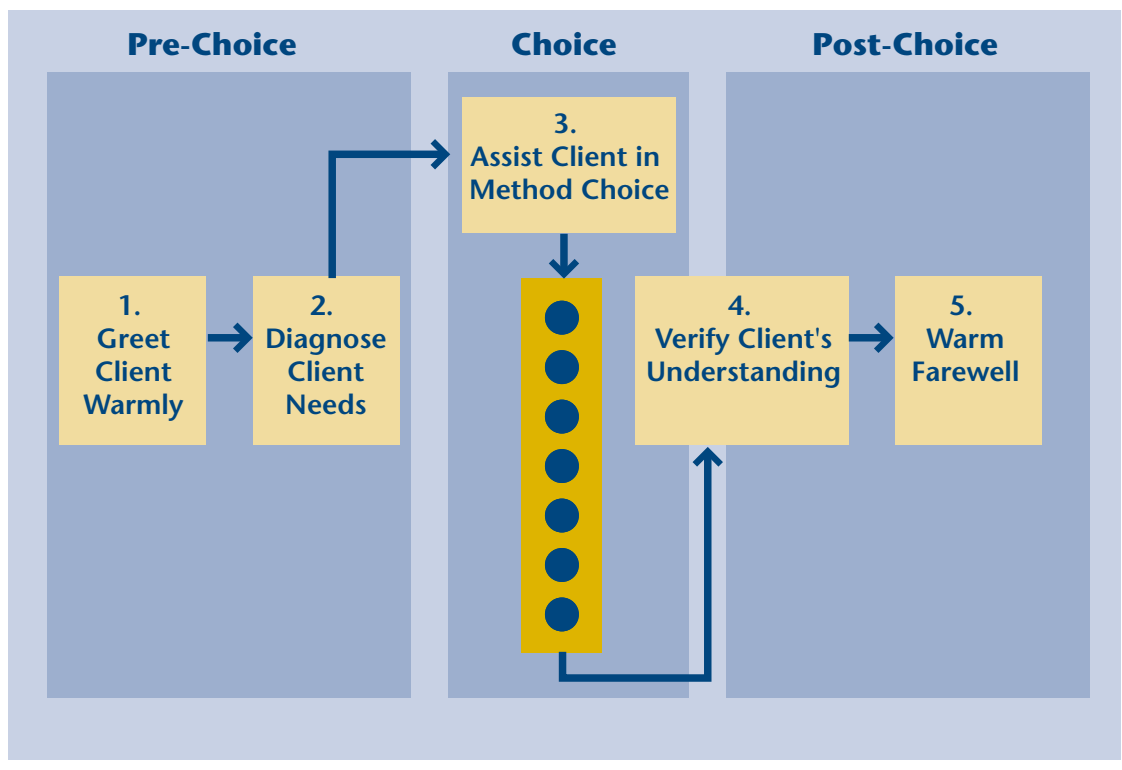

Source: MOH 1999. tance to help the client choose a method; (4) verification that the client understood; and (5) a warm farewell (see Figure 1). Providers were instructed to complete a specific number of tasks and to spend an average of 15 minutes with each client. Most providers had access to a flip chart depicting available methods for use during counseling sessions (MOH 1999).

\section{Assessing the Quality of Counseling}

The $\mathrm{MOH}$ and the Population Council conducted a study in 1999 with two goals: to assess Peruvian providers' compliance with the new guidelines; and to develop methods for monitoring compliance with the guidelines. Three main findings emerged: 
Figure 2. Balanced Counseling Model with Specific Tasks for Providers in Peru

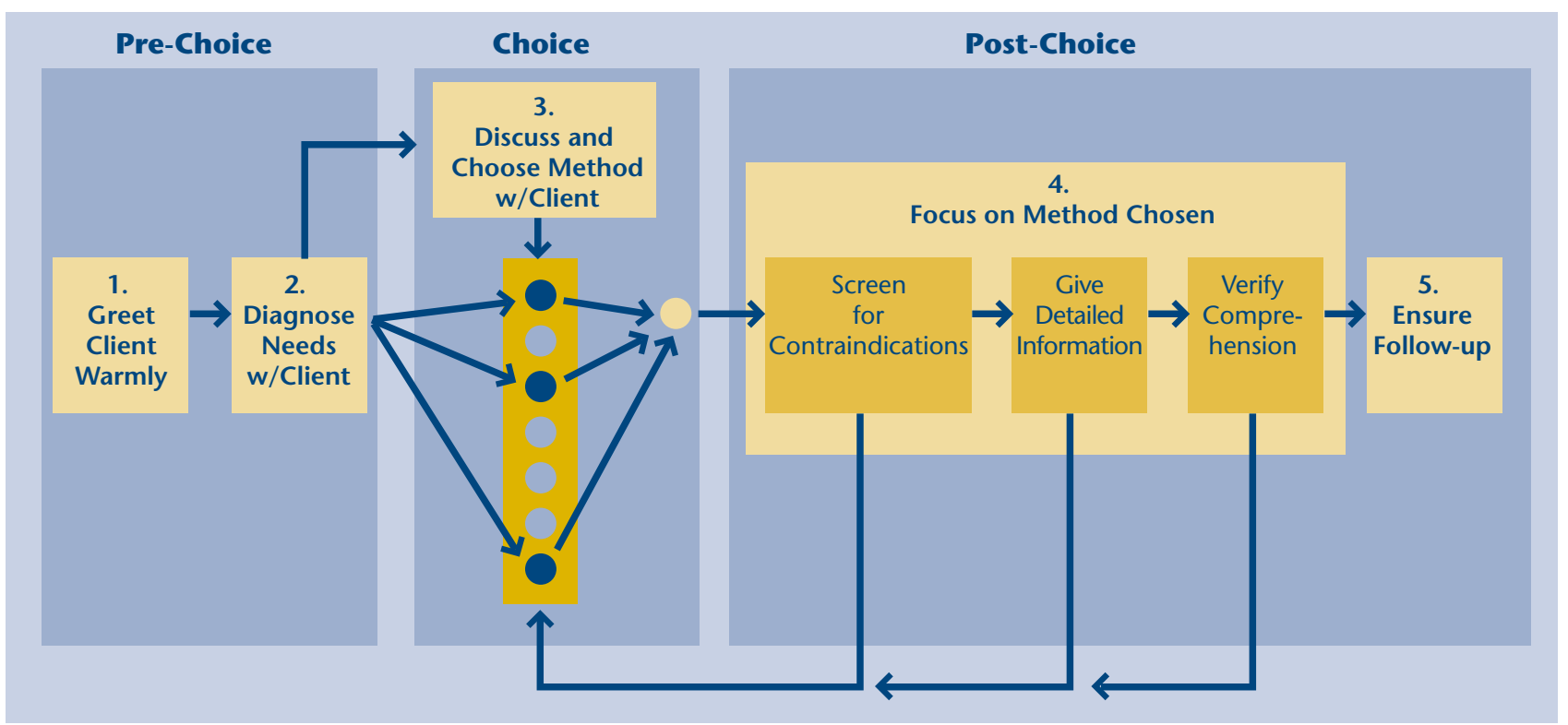

Source: León et al. 2003b.

Providers failed to discuss clients' wishes. At the beginning of the counseling session, providers asked mainly medical questions (such as the date of the client's last menstrual period) and failed to ask the client basic questions about her reproductive intentions-such as whether she wanted more children, or whether her partner cooperated in contraceptive use. Furthermore, the information obtained from the client (such as her blood pressure) often had limited practical use in the selection process.

Providers often gave excessive information. Providers furnished excessive detail on most of the 11 methods available in $\mathrm{MOH}$ clinics-whether or not they suited the client's needs. This overloaded clients with more information than they could remember, and much that they could not use.
- Information provided on the chosen method was sparse.

Most of the counseling time was spent describing numerous method options, while important information for both provider and client-such as contraindications, use instructions, side effects, and warning signs related to the chosen methodwas neglected.

Because of these weaknesses in counseling, clients interviewed after the consultation knew little about the method they had chosen (León et al. 2001; León et al. 2003b). Take-home pamphlets, which might have provided further information for this mainly literate client population, were either unavailable or incomplete.

Two data collection methodsexit interviews with clients as they left the clinic, and the use of trained simulated clients presenting a designated profile and method request-proved reliable for monitoring the content and quality of the client-provider exchange during counseling (León 1999). These two methods were used in subsequent studies.

\section{Improving Opportunities for Choice: The Balanced Counseling Strategy}

To address these counseling weaknesses, the Council worked with the Peruvian $\mathrm{MOH}$ to develop and test a more practical, interactive, and client-friendly strategy that simplified decisionmaking and responded more appropriately to the client's needs and reproductive intentions. This model, the balanced counseling strategy, replaced the existing counseling protocol with a more functional approach focused on quality (see Figure 2):

1. Greet the client warmly;

2. Assess client's needs based on her stated reproductive intentions and, with the client, discard methods that are irrelevant to her needs;

3. From among the remaining methods, offer and discuss a 

Figure 3. Method card presenting the injectable DMPA (front)
and describing four essential aspects of the method (back)

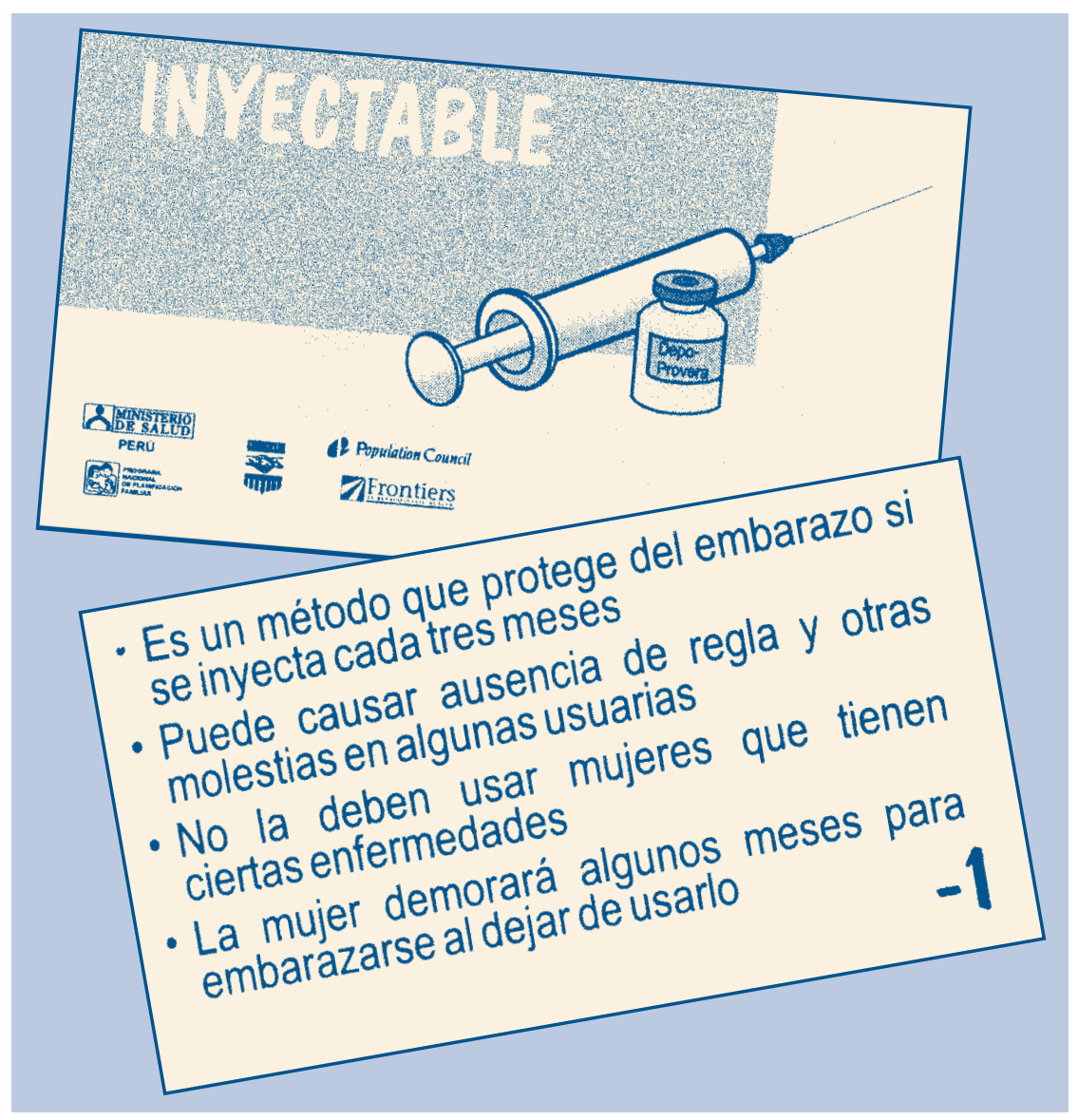

Source: Leon et al. 2003b.

set of methods suited to the client's needs, and ask her to choose a method;

4. Focus on the method chosen, beginning with screening for contraindications (verifying comprehension and choosing an alternative method if necessary), and including detailed information on the use, side effects, and warning signs of the method; and

5. Provide oral and written follow-up instructions to ensure that the client can use the method safely and continuously at home, as long as her reproductive intentions remain stable.

To support provider compliance with the balanced counseling strategy, researchers also developed and pretested three job aids:

\section{A poster describing the new counseling model, with step- by-step guidance for the provider.}

\section{A set of 11 palm-sized cards,} one per contraceptive method offered. (M ethods offered in Peru included the IUD as well as barrier, natural, and hormonal methods. See the sample card on the injectable provider would display the cards at the start of counseling, discard cards for irrelevant methods, and retain those describing relevant methods.

3. A set of 11 four-page pamphlets, one for each method available, describing each method, its use, benefits, disadvantages, and contraindications. Each client receiving a method was to receive the corresponding pamphlet to take home.

\section{Testing the Strategy and Job Aids in Peru}

Between 2000 and 2002 the Population Council conducted an experiment to test the effectiveness of the balanced counseling strategy and the accompanying job aids.

Researchers randomly assigned 12 of Peru's 34 regional health directorates to an experimental group, after matching them to 12 comparable control directorates. The experimental and control directorates were matched on the basis of geography, culture, and client volume. method, Figure 3.) The

\section{Training workshops}

Between June 2000 and March workshops on the balanced counseling strategy. The first workshop, a two-day event, targeted providers and involved about 25 providers from each of the 12 experimental areas. The second workshop involved both MOH family planning coordinators and providers. Coordinators received two days of training and then provided in-service training to providers. Seventyfive family planning coordinators and 278 providers (of whom 2001, project staff conducted two 


\section{Indicators of Quality of Care in Test of Balanced Counseling}

1. Client-provider interaction

2. Adequate needs diagnosis

3. Description of appropriate methods

4. Explanation of contraindications

5. Instructions on method use

6. Description of method's advantages and disadvantages

7. Explanation of side effects and warning signs

8. Arrangements for follow-up

Source: MOH 1999.

$60 \%$ had participated in the first training session) attended the second workshop. Each participating provider received the counseling poster, method cards for use in the clinic, and a year's supply of pamphlets.

\section{Testing the intervention's effects} From April to September 2001, researchers collected data to measure the effect of the intervention. The study compared the performance of providers in the experimental clinics with that of providers in the control clinics. The researchers focused on three aspects of the intervention:

(1) changes in quality of care;

(2) changes in clients' knowledge; and (3) consequences for the services in terms of time and patient flow.
Observers, interviewers, and simulated clients recorded the quality of care provided based on eight sets of indicators derived from the MOH's 1999 guidelines (see Box). Observers of client sessions assessed the quality of the interaction between providers and clients using a checklist based on the indicators.

Simulated clients filled out a more detailed inventory with 72 items pertaining to quality (León et al. 2003b).

\section{Findings}

\section{Quality of care}

Quality of care improved-if providers used the job aids. The post-intervention findings showed statistically significant improvements within the experimental group as a whole, compared to the control group. These improvements were greatest when clients chose the IUD or hormonal methods-possibly because of the greater complexity of instructions for using these methods, compared to routine instructions given for barrier and natural methods. Within the experimental group, the largest improvement took place among providers who used the method cards and the pamphlets. Reports from simulated clients showed that following the intervention, job aids users scored 68 percent higher than experimental providers who did not use job aids-and nearly 83 percent higher than providers in the control group (see Figure 4).

Not all providers used the job aids. Simulated clients reported that 64 percent of providers used one of the two job aids, and only 37 percent used both the cards and the pamphlets. When asked why they failed to use job aids, providers most commonly replied that they did not know about them, or that the aids were not available at the facility.

\section{Figure 4. Quality Scores of Peruvian Providers at Experimental and Control Clinics by Use or Non-Use of Job Aids}

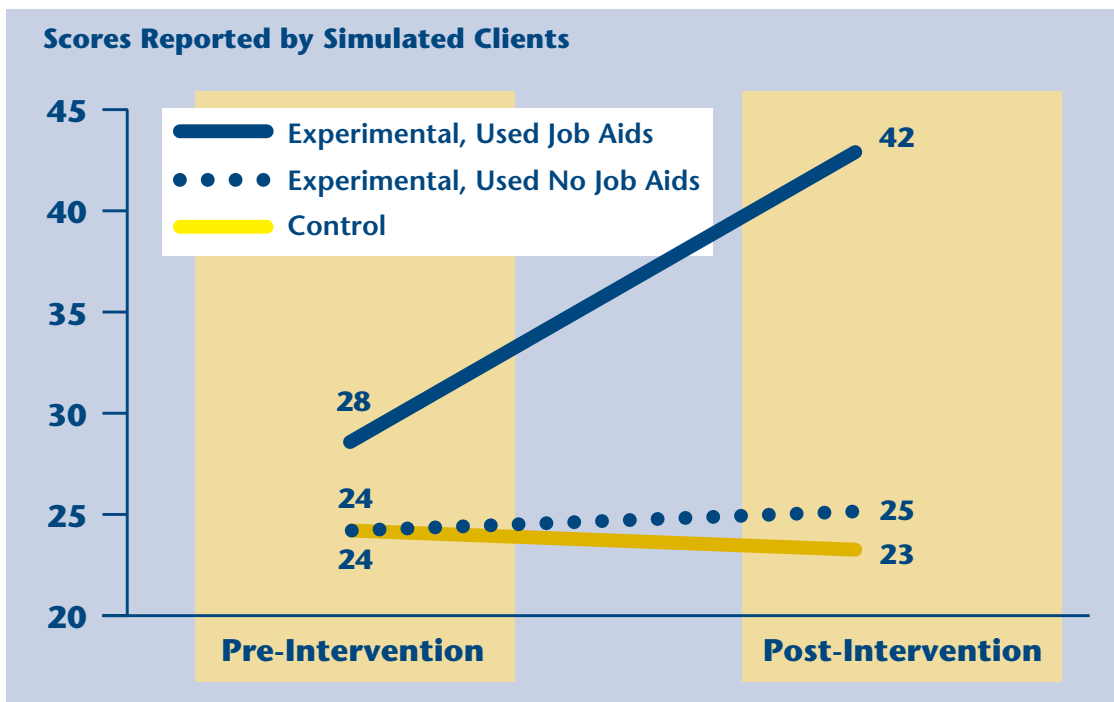

Source: León et al. 2003b. 
The intervention benefited the providers who used the job aids. Providers who did not use the job aids did not benefit from the training (see Figure 4). They performed at about the same level as providers in the control group. The providers who did use the job aids were al ready performing better at the time of the pre-intervention test; their performance improved significantly when they used the counseling strategy combined with the job aids.

Labor status was the most consistent predictor of higher performance. Providers under temporary contracts were more likely to use job aids than tenured employees. Nearly half (46\%) of contract providers used the job aids, compared to only 27 percent of tenured providers. It may be that the absence of secure employment constituted an important incentive for compliance. This is a significant finding because about two-thirds of $\mathrm{MOH}$ providers were contract employees (León et al. 2003b).

\section{Knowledge}

Effects on clients' knowledge were mixed. Researchers assessed clients' knowledge of their chosen method during exit interviews. The knowledge of clients requesting the IUD and hormonal methods was significantly higher when they consulted providers who used the job aids. However, the knowledge of clients who chose other methods did not differ significantly between control and experimental groups.

\section{Consequences to programs}

- Program consequences for providers' time and client flow were acceptable. Use of the balanced counseling strategy and the job aids added an extra four minutes, on average, for each counseling session. The increased time spent, however, did not detract from the number of clients who received family planning service either on a daily or quarterly basis. This is probably because new family planning clients constituted a low proportion of the total clinic clientele (estimated at 10 to 15 percent $^{1}$ ). The intervention did not effect discernable changes in method mix; thus no additional funds were necessary to purchase supplies or methods (León et al. 2003b).
${ }^{1}$ Federico León, personal communication, June 2003.

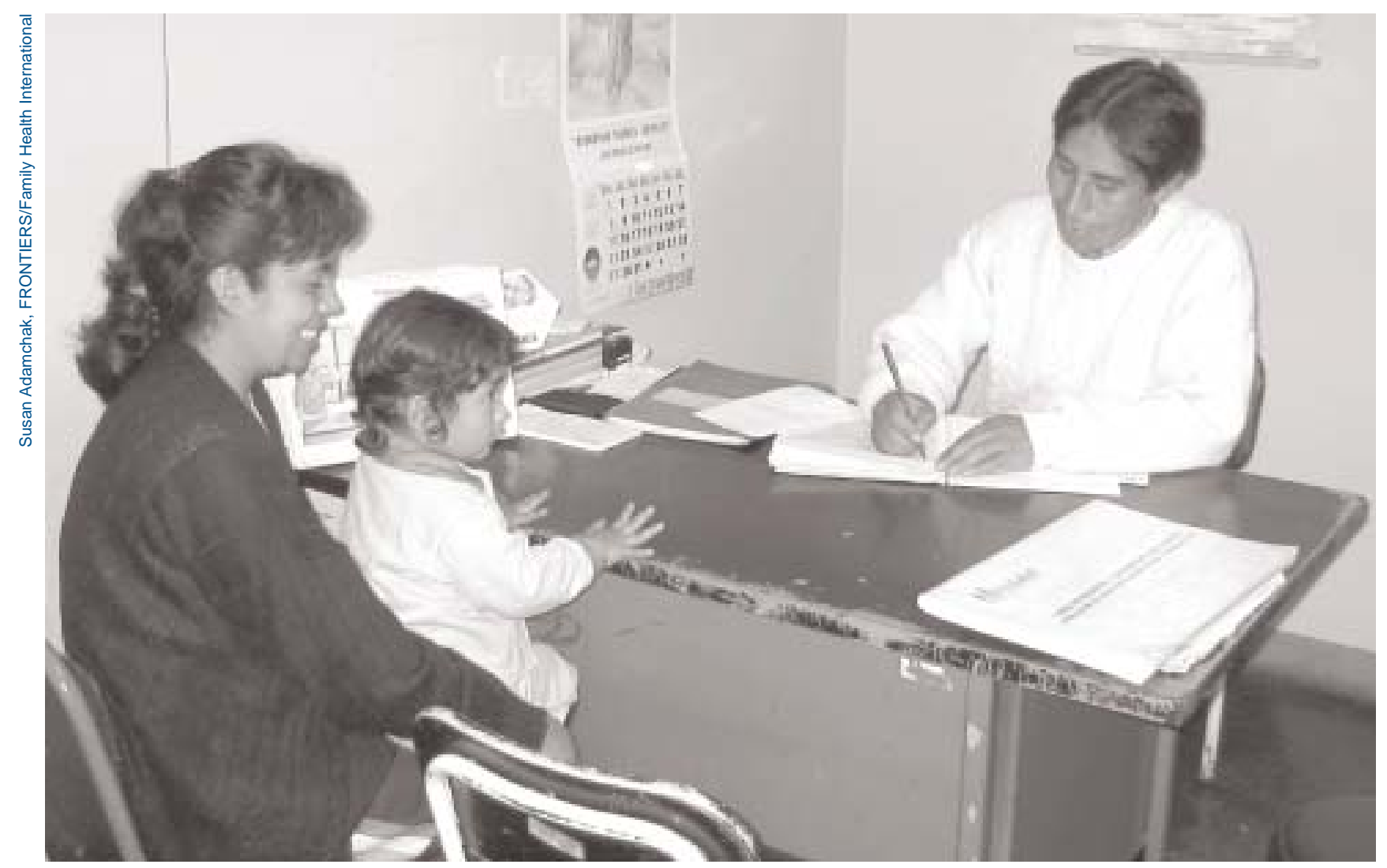

A Peruvian provider counsels a client. 


\section{Costs of the First Year of Implementation}

Researchers also conducted an economic analysis of the costs of implementing the balanced counseling strategy with its accompanying job aids in Peru. The overall cost of designing and implementing the strategy was approximately US\$80,000.

Development of the job aids and training curricula accounted for about $\$ 15,000$ of this cost, while training (time, travel, per diem for consultants and participants, and a one-year supply of job aids) accounted for the remaining $\$ 65,000$. The development costs would likely be much lower in the event of a scale-up.

The review included a sensitivity analysis to determine the cost of reproducing the job aids in the large numbers typical of a largerscale implementation. During the experimental phase, the project produced 200,000 method pamphlets to supply about 300 clinics; but a scale-up process will involve as many as 2,000 clinics. The per-unit cost of the job aids decreases as more are produced. For example, a set of job aids for each provider (including 11 method cards and a poster) costs $\$ 0.50$ per set for 1,000 sets (totaling $\$ 500$ ), and $\$ 0.20$ per set if 10,000 sets are produced (for a total of $\$ 2,000$ ). The per-unit cost of each method pamphlet is $\$ 0.03$ if 100,000 pamphlets are printed, but drops to $\$ 0.02$ if 500,000 are produced (for a total of $\$ 10,000)$. It is vital to understand and incorporate these costs in planning for broader implementation, as the presence and use of the job aids significantly improve providers' performance. ${ }^{2}$

\section{Expanding the Strategy: Replication and Scale-up}

The findings from the studies in Peru were disseminated to key stakeholders in and beyond Peru by means of regular bulletins. This dissemination not only helped stimulate efforts to scale up the use of the counseling strategy within Peru, but also generated an opportunity to test the balanced counseling strategy in other settings.

\section{Replication in Guatemala}

In late 2000, based on the findings reported in the initial progress bulletins and personal presentations on the Peru intervention, the Guatemalan government expressed interest in testing the counseling strategy and the job aids for use within the Guatemalan context.

\section{Ministry of Public Health and Social Assistance}

In mid-2001, the Guatemalan Ministry of Public Health and Social Assistance (MSPAS) began working with Calidad en Salud (Quality in Health), a project implemented by the University Research Co., LLC and supported by the U.S. Agency for International Development (USAID), to test the effectiveness of the balanced counseling strategy and job aids among providers at Guatemalan health centers and rural health posts. In contrast to Peru, where providers are generally obstetric nurses with university degrees, most providers in Guatemala are paraprofessionals: auxiliary nurses with two years of training.
For this group of providers, researchers, trainers, and health authorities developed a 22-step algorithm offering detailed instructions, eight method cards corresponding to the methods offered at MSPAS health centers, and one card for ruling out pregnancy. Providers in the Guatemalan study received four revisits to reinforce training on the use of the algorithm and job aids. Supervisory nurses from the participating health districts were also trained in the use of the algorithm and job aids, and were instructed to monitor its use and offer feedback on the interaction between providers and clients.

Approximately 320 providers from 40 health centers and posts in two departments (administrative regions) populated by Mayan- or Spanish-speaking ethnic groups received training in the algorithm and the use of the method cards and pamphlets. At 40 control facilities (located in two departments with demographically similar populations), providers received only the method pamphlets. Simulated clients enacting two profiles visited both experimental and control clinics, and filled out checklists to assess the quality of care before and after the intervention. 
Figure 5. Average Quality Scores of Providers at Experimental and Control Clinics in Guatemala

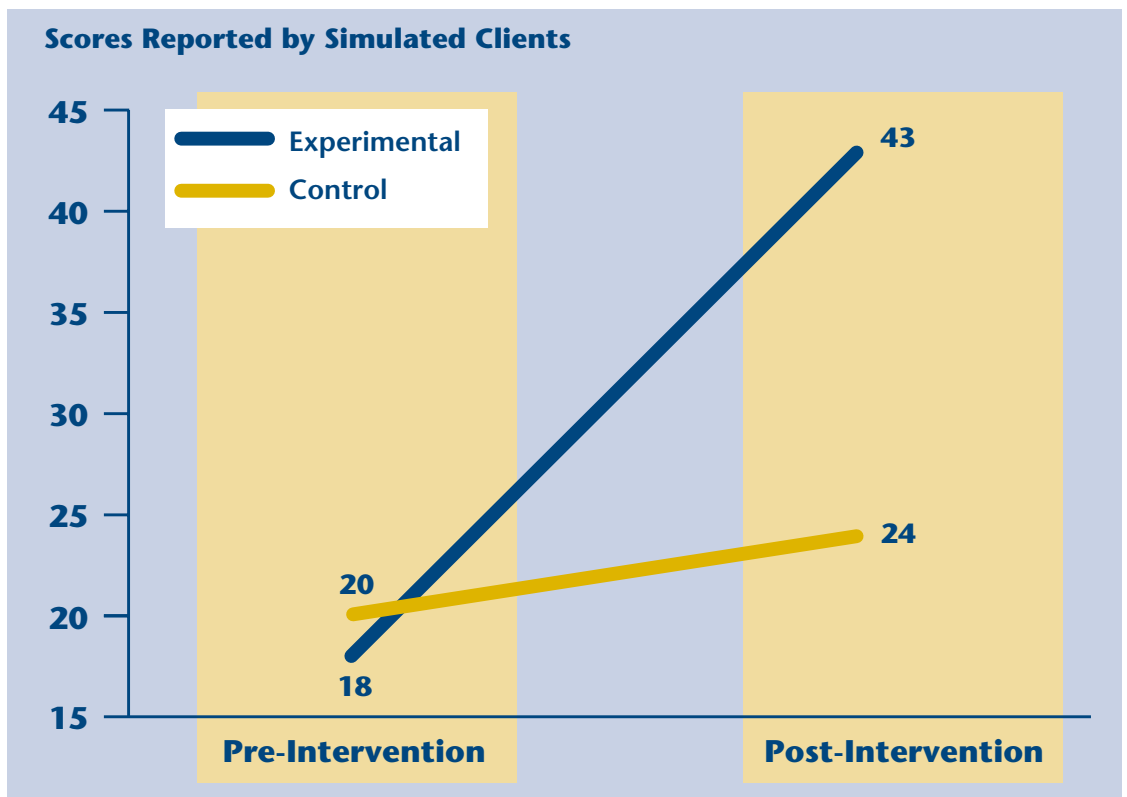

Source: León et al. 2003a.

\section{Findings}

Quality of care improved. The quality of care improved significantly among the experimental clinics following the intervention. Mean quality of care scores, as rated by simulated clients, increased from 18 to 43 of a possible 65 points in the experimental sites. This represents an increase of about 80 percent over the control sites. At control sites, the mean scores increased from 20 to only 24 (see Figure 5).

Most providers used the algorithm and job aids. Simulated clients reported that nearly threequarters $(72 \%)$ of the providers in the experimental facilities used the al gorithm with both job aids. Eighty-five percent of the providers used the method cards. The main reason for not using the method pamphlets, according to Guatemalan providers, was that they were not available at the time. This result is considerably better than the 37 percent use achieved in Peru and suggests important reinforcement of the training.

Time used during each session increased. Counseling session length increased from 12 to 14 minutes in the control group and from 13 to 24 minutes in the experimental group. Improvements in quality of care were associated with the increased counseling length. As in Peru, increased counseling time is unlikely to hinder client flow, as long as the proportion of new users remains around 10 to 15 percent (León et al. 2003a). that the four revisits provided
Beginning in January 2003 MPSAS and Calidad en Salud expanded training in the use of the balanced counseling strategy to 3,600 service providers throughout Guatemala. The results of this expansion will be available on completion of the activity in 2004.

\section{Institute of Social Security} In spring 2001, the Guatemal an Institute of Social Security (IGSS) tested the strategy and job aids for use in its Gynecology and Obstetrics Hospital, a large facility in Guatemala City that provides family planning to over 12,000 postpartum and postabortion clients annually.

IGSS worked with Calidad en Salud to adapt the MSPAS al gorithm and job aids for use among its clients. Preliminary findings showed significant improvements in quality of care. Clients' knowledge about their chosen method increased following the intervention (León and Ríos 2003). Knowledge about preventing sexually transmitted infections also increased. IGSS is conducting activities to scale up the intervention at six more IGSS hospitals that provide services to 95 percent of family planning users served by the institute. 


\section{Scale-up in Peru}

The Peruvian $\mathrm{MOH}$ began

preparations to scale up use of the balanced counseling strategy in early 2001 based on encouraging preliminary findings. The Ministry printed posters describing the balanced counseling strategy and reproduced the method cards and pamphlets for use during counseling sessions. The job aids were distributed to facilities in all the 12 experimental districts. It is anticipated that the $\mathrm{MOH}$ will incorporate the strategy into its training plans and revise its guidelines for family planning counseling to include the strategy and job aids nation wide.
While research on the new counseling model was still underway, Peru's MOH shifted its emphasis from family planning to an integrated approach to reproductive health services. A test of the balanced counseling strategy at EsSalud, the former Institute of Social Security of Peru, showed that the strategy could be incorporated into an integrated care model. As part of the dissemination process, the Council presented three one-day workshops at EsSalud clinics to introduce the balanced counseling strategy and the operations research approach.
EsSalud adapted the strategy using the algorithms developed in Guatemala. They expanded the algorith ms to incorporate various aspects of reproductive health and conducted a limited test on 15 experimental providers and 15 control providers in the department of Lima. The intervention improved the quality of care provided during counseling. However, providers did not implement the counseling strategy unless they were being observed. When asked why they did not use the strategy, the providers said that its use would add too much time to counseling sessions, and that they were uncertain of the strategy's benefits. Nevertheless, EsSalud found sufficient positive results to request assistance in scaling up the use of the strategy.

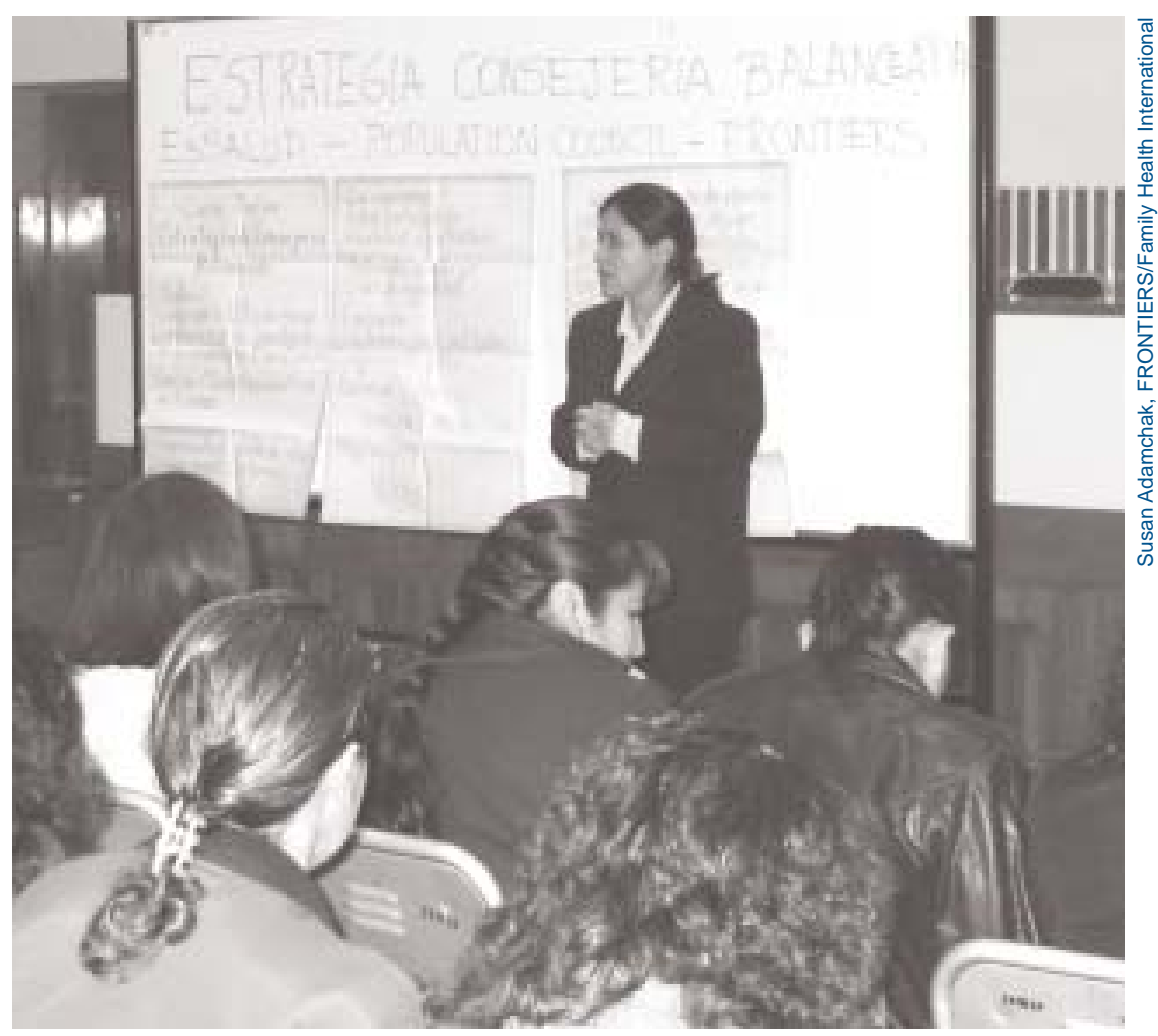

Peruvian providers at a training session. 


\section{Lessons Learned}

The studies in Peru and Guatemala suggest the following findings on improving client choice, and hence quality of care, by implementing the balanced counseling strategy with accompanying job aids:

The balanced counseling strategy improves the quality of family planning counselingwhen providers use the job aids.

Nonprofessional or paraprofessional providers are capable of using al gorithms such as the balanced counseling strategy when they receive sufficient training.

Though use of the balanced counseling strategy increases the quality of family planning counseling, there is still room for improvement. Average scores on quality indicators, as recorded by simulated clients, reached only half the maximum in Peru and two-thirds of the maximum in Guatemala. Increasing the availability of method pamphlets, improving supervision to enhance use of the method cards and pamphlets, and strengthening the algorithm and job aids could help improve the quality of care provided.

Intensity of training affects compliance. The Peruvian providers were first exposed to the strategy in a two-day workshop, then received a one-day training workshop on the use of the balanced counseling strategy and the job aids. In contrast, the Guatemalan providers participated in a one-day workshop followed by four reinforcing revisits.
Researchers believe that the close and continual supervision provided in the Guatemala interventions contributed to the high level of compliance and resulting quality improvements made at the experimental clinics.

Institutional leadership reinforces compliance. Though Peruvian $\mathrm{MOH}$ authorities expressed their commitment to the innovation, field observations suggested that institutional involvement was not apparent after the experiment began. In Guatemala, by contrast, the MPSAS and health area directors accompanied the intervention team during the revisits to the trained providers. This probably increased providers' perception of higher-level support and involvement.

\section{Conclusions}

Studies conducted to date on the balanced counseling strategy show that when used with the job aids, this model can improve both the quality of the provider's counseling and the client's ability to make an informed decision about the most appropriate contraceptive method for her needs. The strategy is adaptable and has been replicated with improved results. Further research and systematic scale-up in Peru and Guatemala, already underway, will determine ways of refining and improving the strategy. 


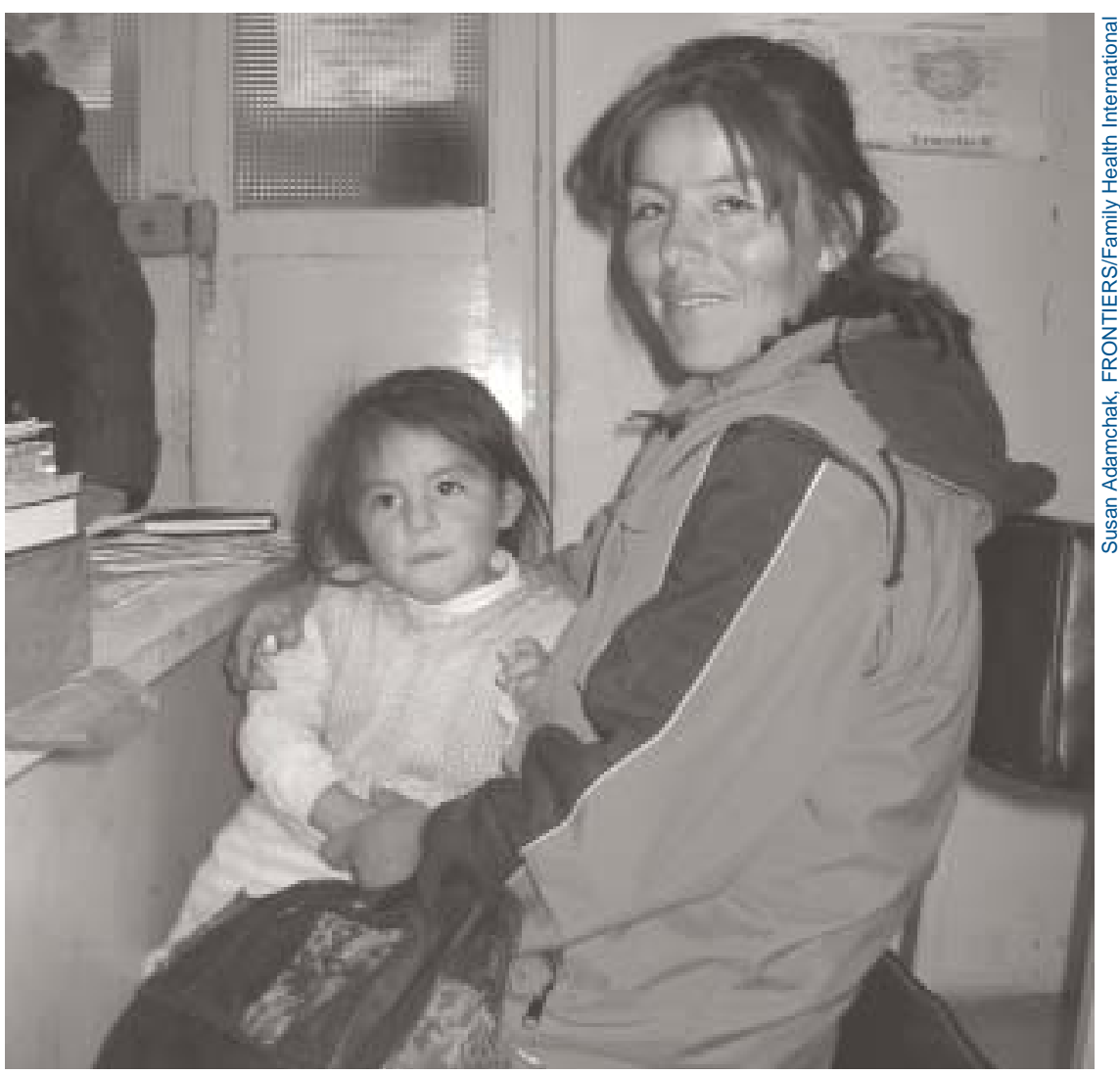

\section{References}

Bruce, Judith. 1990.

"Fundamental Elements of

Quality of Care: A Simple

Framework," Studies in Family

Planning 21(2): 61-91.

León, Federico R. 1999.

“Peru: Providers' Compliance with Quality of Care Norms," FRONTIERS Final Report.

Washington, D.C.: Population Council.

León, Federico R. et al. 2001.

"Counseling Sessions Length and Amount of Relevant Information Exchanged in Peruvian Clinics," International Family Planning Perspectives 27(1): 28-33 \& 46.
León, Federico R. 2002.

"Introducing the Job AidsAssisted Balanced Counseling Strategy: A Test in Peru MOH Clinics," paper presented at the annual meeting of the American Public Health Association, November.

León, Federico R. and Alex Ríos. 2003. "Balanced Counseling Strategy Reversed Negative Trend at the IGSS," FRONTIERS Peru PCI-QoC Project Bulletin No. 24, May 15. Lima: Population Council.
León, Federico R. et al. 2003a. “Improving Provider-Client Interactions at Guatemalan $\mathrm{MOH}$ Clinics: Extent and Cost," FRONTIERS Final Report. Washington, D.C.: Population Council.

León, Federico R. et al. 2003b. “Improving Provider-Client Interactions at Peru $\mathrm{MOH}$ Clinics: Extent, Benefit, and Cost," FRONTIERS Final Report. Washington, D.C.: Population Council.

Peru Ministry of Health. 1999. Manual de Consejería de Planificación Familiar [Manual of Family Counseling]. Lima: Ministerio de Salud, Dirección General de Salud de las Personas. 
FRONTIERS The Frontiers in Reproductive Health IN REPRODUCTIVE HEALTH Program (FRONTIERS) applies systematic research techniques to improve delivery

of family planning and reproductive health services and influence related policies. FRONTIERS is funded by the U.S. Agency for Intemational Development (USAID) and led by the Population Council in collaboration with Family Health Intemational and Tulane University.

\section{Population Council an intemational, nouncil is nongovemmental institu-}

tion that seeks to improve the well-being and reproductive health of current and future generations around the world and to help achieve a humane, equitable, and sustainable balance between people and resources. The Council conducts biomedical, social science, and public health research and helps build research capacities in developing countries. Established in 1952, the Council is govemed by an international board of trustees. Its New York headquarters supports a global network of regional and country offices.

Frontiers in Reproductive Health

Population Council

4301 Connecticut Ave. N.W., Suite 280

Washington, D.C. 20008 U.S.A.

telephone: (202) 237-9400

toll free: (877) 237-9400

facsimile: (202) 237-8410

e-mail: frontiers@pcdc.org

www.popcouncil.org/frontiers/

This publication was made possible through support provided by USAID under the terms of Cooperative Agreement No. HRN-A-00-98-00012. The opinions expressed herein do not necessarily reflect the views of USAID.

(c) 2003 by the Population Council, Inc. All rights reserved.

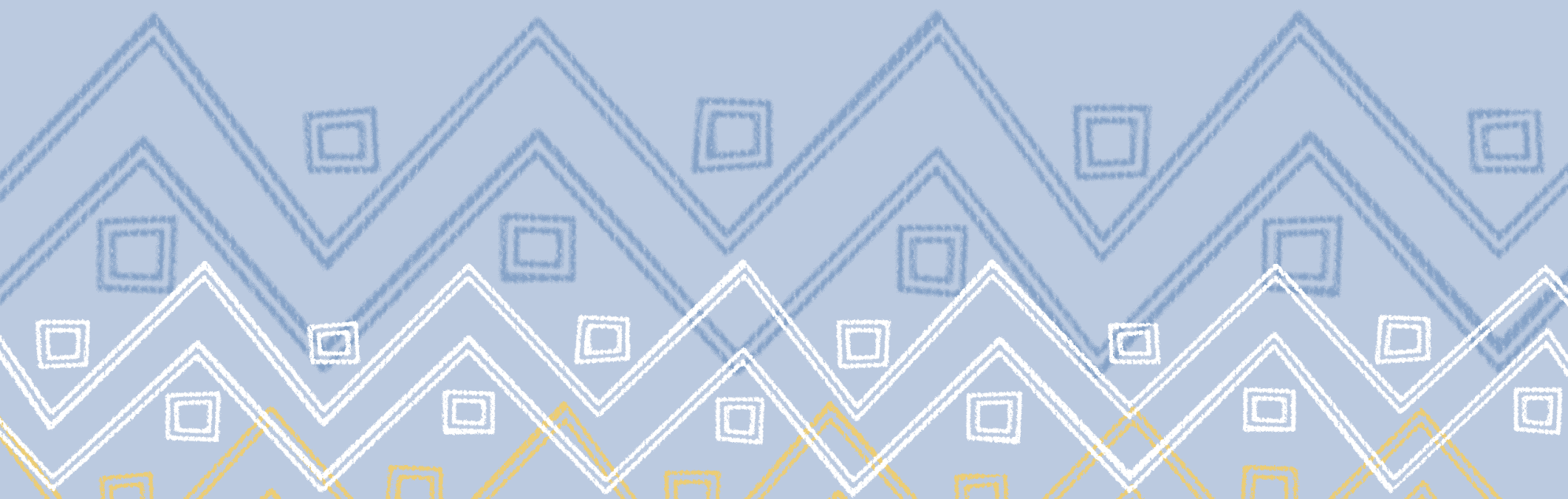

